\title{
A discussion with digital health pioneer Dr. Eric Topol
}

$\mathrm{D}$ igital health pioneer Dr. Eric Topol was the most influential physician executive in the United States in 2012, according to a national poll by Modern Healthcare. Topol is a professor of genomics and the Gary and Mary West Endowed Chair of Innovative Medicine at the Scripps Research Institute in La Jolla, California. He has published more than 1100 peer-reviewed articles and 30 medical textbooks. His 2012 book, The Creative Destruction of Medicine: How the Digital Revolution Will Create Better Health Care, charts the impact of genomics, wireless sensors, mobile devices and other digital heath information technologies on preventive medicine.

$C M A J$ spoke with Topol in Ottawa, Ontario, where he gave the keynote address at eHealth 2013, a national conference on ehealth.

CMAJ: Why do you say we are at a "unique inflection point for medicine?"

Topol: We have this phenomenal data infrastructure, with the bandwidth and the connectivity and cloud computing and mobile devices, that exists now and is continuing to mature. At the same time, we have these tools to be able to zoom in on each person to define their medical essence, like genomics and biosensors and scanners.

CMAJ: Describe the benefits of being what you term a "digitized person."

Topol: The digitized human being is: you know so much about an individual before they take ill that you can prevent them from becoming ill. Let's say you define someone genomically - along with their family history — as very high risk for asthma. And we know a lot of

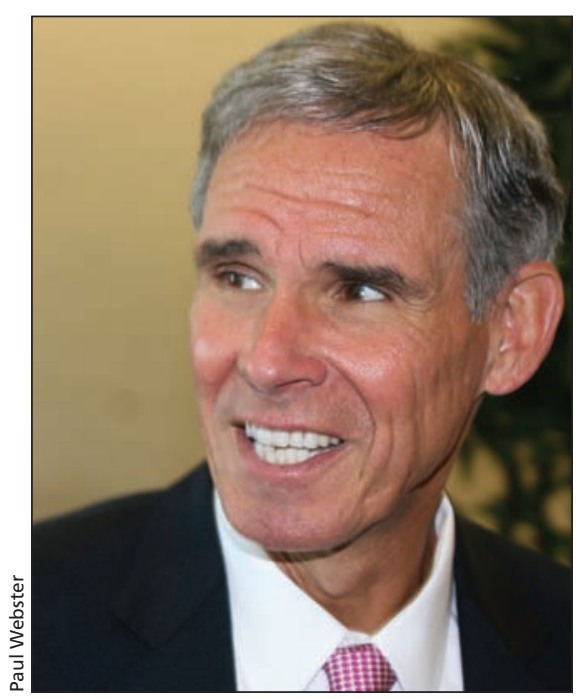

Digital health pioneer Dr. Eric Topol is considered one of the most influential physician executives in the United States.

kids die of asthma. At the same time, you have sensors to pick up signs that their airways are starting to constrict long before they even have a wheeze.

\section{CMAJ: What is "cyber-chondria?"}

Topol: It's basically a too-muchinformation story, whereby you have a lot of information that's inducing anxiety [in patients], coming electronically through mobile devices and sensors connected to them. It's an unfortunate downside of having all this data available. If there are people who are especially anxious individuals, they may not be so well-suited for this type of data capture.

CMAJ: How reliable are patients in inputting and managing their own health data?

Topol: What I've been impressed with in the products out there or in the hopper is that the patients and individuals using them become data-driven because they are so easy to use and captivating. Those suspects least likely to be interested in their data all of a sudden are the ultra-converted. All of these people I could never get a blood pressure from, now I'm getting hundreds per week.

CMAJ: To what extent is the physician replaceable with technology?

Topol: That remains to be seen. My main thesis is that, overall, physicians will not be replaced, but rather they will be morphed to a different model of how they provide care: a partnership model, where a very high proportion of the data flows directly to the individual [physician] and to the patient.

CMAJ: What's your vision of what you call "the democratization of medicine?"

Topol: The public has not had that access [to their medical information] and they're going to now. The direct access to information is a liberation, an emancipation of data and information that will be extraordinary.

CMAJ: What is the "consumer revolution" you see under way in medicine?

Topol: The consumer-driven revolution is being able to bypass a doctor to get information about, for example, skin lesions, ear drum inspection, getting your eyes refracted. There's going to be hundreds of these sorts of things. - Paul Webster, Ottawa, Ont.

CMAJ 2013. DOI:10.1503/cmaj.109-4546 